\title{
CARBOHYDRATE AND LIPID METABOLIC PROFILES OF TUBERCULOSIS PATIENTS WITH BILATERAL PULMONARY LESIONS AND MYCOBACTERIA EXCRETION
}

DOI: 10.36740/WLek202007113

\author{
Olga M. Shvets' ${ }^{1}$, Olga S. Shevchenko', Liliia D. Todoriko ${ }^{2}$, Rostyslav S. Shevchenko' ${ }^{1}$, Volodumur V. Yakimets ${ }^{3}$, \\ Oleksandra I. Choporova' ${ }^{1}$ Ganna L. Stepanenko' ${ }^{1}$ \\ ${ }^{1}$ KHARKIV NATIONAL MEDICAL UNIVERSITY, KHARKIV, UKRAINE \\ ${ }^{2}$ BUKOVINIAN STATE MEDICAL UNIVERSITY, CHERNIVTSI, UKRAINE \\ ${ }^{3}$ RIVNE REGIONAL CLINICAL MEDICAL AND DIAGNOSTIC CENTER NAMED AFTER VICTOR POLISHCHU, RIVNE, UKRAINE
}

\begin{abstract}
The aim: To assess carbohydrate and lipid metabolic profiles of tuberculosis patients with bilateral injuries of the lungs and mycobacteria excretion. Materials and methods: Seventy two newly diagnosed pulmonary TB patients were examined. Group I - 17 newly diagnosed TB patients who had unilateral pulmonary lesions and had no mycobacteria excretion. Group II - 55 newly diagnosed TB patients who had bilateral pulmonary lesions and mycobacteria excretion. The control group included 20 healthy persons. Fasting insulin level, indices of lipidogram were measured, oral glucose tolerance test was performed. Statistical processing of the obtained results was carried out by analyzing the contingency tables using the StatisticaBasicAcademic 13 for Windows software package.

Results: Tuberculosis patients develop insulin resistance - condition that is a precursor to developing type 2 diabetes and metabolic disorder of lipid exchange - dyslipidemia. Patients with bilateral pulmonary lesions and mycobacteria excretion have the most pronounced disorders of carbohydrate and lipid metabolism compared to patients with limited lesions of the lungs.

Conclusions: We suppose that mycobacteria excretion and bilateral lesions of lungs may be the markers of the degree of carbohydrate and lipid metabolism disorders in patients with pulmonary tuberculosis.
\end{abstract}

KEY WORDS: pulmonary tuberculosis, mycobacteria excretion, glucose metabolism, lipidogram

\section{INTRODUCTION}

Diabetes mellitus (DM) leads to increased susceptibility to tuberculosis (TB) via multiple mechanisms. The mechanisms include those directly related to hyperglycaemia and cellular insulinopenia, as well as indirect effects on macrophage and lymphocyte function. DM is known to affect chemotaxis, phagocytosis, activation, and antigen presentation by phagocytes in response to $\mathrm{M}$. tuberculosis [1]. But the linkbetween DM and TB is bidirectional. TB can lead to impaired glucose tolerance (IGT) and new onset DM [2]. Dysglycemia in TB patients might be the result of stress response to infection, though dedicated studies to assess whether TB increases the risk of diabetes are still few.

\section{THE AIM}

The study was performed to assess changes in carbohydrate and lipid metabolic profiles in tuberculosis patients with bilateral lesions of the lungs and mycobacteria excretion.

\section{MATERIALS AND METHODS}

We examined 72 newly diagnosed pulmonary TB patients, who were treated in Kharkiv Regional TB Dispensary No.
1 from 2016 to 2017. Those patients who had HIV/TB co-infection, TB/DM comorbidity and body mass index (BMI) $>25$ were excluded from the study. Depending on the mycobacteria excretion, which was confirmed by sputum microscopy and sputum culture test, and the extent of pathological changes in the lungs on X-ray, patients were divided into groups. The control group included 20 healthy persons, which were correlated with the comparison groups by gender and age.

Additionally we performed oral glucose tolerance test (OGTT) and measured fasting insulin level. Also, indices of lipidogram were measured: total cholesterol, high-density lipoproteins (HDL), low-density lipoproteins (LDL), very low density lipoproteins (VLDL), triglycerides and atherogenicity index (AI). BMI and HOMA-IR were calculated.

Statistical processing of the obtained results was carried out by analyzing the contingency tables using the StatisticaBasicAcademic 13 for Windows software package. We used the median $(\mathrm{Me})$ interquartile range (Lower - lower quartile, Upper - upper quartile) and sample size (min minimum, max - maximum value). The difference between groups was determined by non-parametric statistics using the Kolmogorov-Smirnov test and Mann-Whitney test 
Table 1. Signs and symptoms on admission

\begin{tabular}{ccc}
\hline Signs and symptoms & $\begin{array}{c}\text { Group I } \\
\text { (unilateral } \\
\text { lesions, MTB-) } \\
\mathbf{n = 1 7}\end{array}$ & $\begin{array}{c}\text { Group II } \\
\text { (bilateral } \\
\text { lesions, MTB+) } \\
\mathbf{n = 5 5}\end{array}$ \\
\hline Fatigue & $11(64.7 \%)$ & $31(56.4 \%)$ \\
\hline Loss of appetite & $3(17.6 \%)$ & $5(9.1 \%)$ \\
\hline Fever & $5(29.4 \%)$ & $38(69.31 \%)$ \\
\hline Night sweats & $5(29.4 \%)$ & $20(36.4 \%)$ \\
\hline $\begin{array}{c}\text { Coughing that lasts three or } \\
\text { more weeks }\end{array}$ & $5(29.4 \%)$ & $30(54.5 \%)$ \\
\hline $\begin{array}{c}\text { Chest pain, or pain with } \\
\text { breathing or coughing }\end{array}$ & 0 & $3(5.5 \%)$ \\
\hline Unintentional weight loss & 0 & $8(14.5 \%)$ \\
\hline
\end{tabular}

criteria (MWC). To study the independent variables, we used the non-parametric Kruskal-Wallis test criteria and the median test.

The work was performed according to the requirements for researches with the participation of people: Statute of the Ukrainian Association for Bioethics and the GCP norms (1992), requirements and norms of ICH GLP (2002), typical ethics provisions of the Ministry of Public Health of Ukraine 66 dated February 13, 2006.

\section{RESULTS AND DISCUSSION}

Group I consisted of 17 newly diagnosed TB patients who had unilateral pulmonary lesions and had no mycobacteria excretion (23.6\%). Group II included 55 newly diagnosed TB patients who had bilateral pulmonary lesions and mycobacteria excretion (76.4\%). Age and sex distribution were nearly the same in both groups. Age ranged from 19 to 58. Men prevailed in both groups: 11 $(64.7 \%)$ and $44(80 \%)$ respectively. The overwhelming majority of Group I patients were hospitalized to the TB hospital in satisfactory condition. Clinical course of the Group II patients was aggravated. They were often complained of signs and symptoms typical for active pulmonary tuberculosis. More detailed information presented in the Table 1.

Infiltrative TB was diagnosed in sixteen patients (94.1\%) from group I and in fifty three patients $(96.4 \%)$. One patient from group I (5.9\%) was diagnosed with miliary TB and two patients (3.8\%) from group II had fibrous-cavernous TB.

In group I patients pulmonary lesions on X-Ray, mainly were localized within one lobe $(88.2 \%)$, cavitation had three patients (17.6\%). All patients from group II had lung cavitation and the multiple decay cavities of various sizes were prevailed $-81.8 \%$ (45 patients).

BMI was within normal ranges in most patients of both groups, though 10 patients from Group II (18.2\%) had expressed underweight $(\mathrm{BMI}<16.0)$.

When comparing medians of the carbohydrate profile indicators of TB patients and healthy controls (Table 2.), we found that the median of fasting glucose levels were within normal ranges $(3.5-5.3 \mathrm{mmol} / \mathrm{L})$ in both groups, though it was higher among TB patients $(5.1 \mathrm{mmol} / \mathrm{L}$ vs $3.9 \mathrm{mmol} / \mathrm{L}$ ). But these differences were not significant ( $p>0.01, \mathrm{CMW})$. Oral glucose tolerance test revealed that the median of postprandial glucose levels did not have significant differences $(4.3 \mathrm{mmol} / \mathrm{L}$ vs $4.0 \mathrm{mmol} / \mathrm{L})$. We found statistically significant difference $(\mathrm{p}<0.01, \mathrm{CMW})$ in median of fasting insulin levels of TB patients and healthy controls ( $16.15 \mathrm{mcU} / \mathrm{ml}$ vs. $4.8 \mathrm{mcU} / \mathrm{ml})$. HOMA-IR also was statistically significantly higher $(\mathrm{p}<0.01, \mathrm{CMW})$ among TB patients (5.8 vs. 0.8). Medians of lipid metabolism indices of TB patients and healthy controls were within normal ranges(Table 2.), except atherogenicity index which was significantly higher $(\mathrm{p}<0.01, \mathrm{CMW})$ among the group of patients (2.8 vs 1.5). This changes were associated with elevated total cholesterol level among TB patients compared to healthy controls ( $4.3 \mathrm{vs} 3.8 \mathrm{mmol} / \mathrm{L}$ ) and decreased level of HDL ( $1.0 \mathrm{vs} 1.3 \mathrm{mmol} / \mathrm{L}$ ). At the same time, we found an increase in median level of LDL in the group of TB patients (2.4 vs $1.7 \mathrm{mmol} / \mathrm{L}$ ).

When comparing the results obtained in groups of patients, we found that among patients of group II, who had bilateral pulmonary lesions and mycobacteria excretion, pronounced metabolic changes were revealed. The median of fasting glucose levels was significantly higher $(\mathrm{p}<0.01, \mathrm{CMW})$ among group II patients $(5.4 \mathrm{mmol} / \mathrm{L}$ vs $4.2 \mathrm{mmol} / \mathrm{L}$ ). Postprandial glucose levels during oral glucose tolerance test did not have significant differences but the median meaning was also higher among group II patients $(5.1 \mathrm{mmol} / \mathrm{L}$ vs $4.2 \mathrm{mmol} / \mathrm{L})$. The median of fasting insulin levels was significantly higher $(\mathrm{p}<0.01, \mathrm{CMW})$ in group II patients $(26.2 \mathrm{mcU} / \mathrm{ml}$ vs. $10.8 \mathrm{mcU} / \mathrm{ml})$ and it is even exceeded normal ranges $(2 \mathrm{mcU} / \mathrm{ml}-25 \mathrm{mcU} / \mathrm{ml})$. HOMA-IR also was significantly higher $(\mathrm{p}<0.01, \mathrm{CMW})$ among patients who had bilateral pulmonary lesions and mycobacteria excretion (6.8 vs. 2.6).

The median of total cholesterol level exceeded the norm in group II and it was significantly higher compering to the results of group I patients ( $5.6 \mathrm{vs} 4.0 \mathrm{mmol} / \mathrm{L}$ ). Level of HDL was within normal ranges and had no significant differences between groups ( $1.2 \mathrm{vs} 1.0 \mathrm{mmol} / \mathrm{L})$. The median level of LDL in both groups also were within normal ranges but the results of group II were significantly higher comparing to the group I ( $3.2 \mathrm{vs} 2.1 \mathrm{mmol} / \mathrm{L})$. Atherogenicity index excided the norm in both groups and was higher in group II patients (3.2 vs 2.8$)(\mathrm{p}<0.01, \mathrm{CMW})$.

Studies show that many people with type 2 diabetes also suffer from interstitial lung disease. The pro-inflammatory, proliferative, and oxidative properties of hyperglycemia have been shown to have an important role in affecting pulmonary vasculature, airways, and lung parenchyma [3-5]. But inflammatory lung diseases also can be a reason of glucose metabolism disorders. Findings of Cyphert $\mathrm{TJ}$ and others show that targeted induction of low-grade inflammation in the lung airway epithelium that does not result in systemic hypoxemia triggers systemic insulin resistance [6]. The same findings were revealed during our study, patients with newly diagnose pulmonary TB had 
Table II. Glucose and lipid metabolism indices in pulmonary TB patients and control group

\begin{tabular}{|c|c|c|c|c|c|c|c|}
\hline Parameter, (units) & mean & median & $\min$ & $\max$ & Lower & upper & Stn.dev. \\
\hline \multicolumn{8}{|c|}{ pulmonary TB patients } \\
\hline $\begin{array}{l}\text { Fasting blood glucose level, } \\
\qquad(\mathrm{mmol} / \mathrm{L})\end{array}$ & 5.3 & 5.1 & 2.4 & 10.5 & 4.7 & 5.6 & 1.7 \\
\hline 2-hour glucose level, (mmol/L) & 4.92 & 4.3 & 2.8 & 9.8 & 3.6 & 6.2 & 1.7 \\
\hline $\begin{array}{l}\text { Fasting blood insulin level, } \\
(\mathrm{mcU} / \mathrm{ml})\end{array}$ & 18.2 & 16.5 & 1.8 & 53.3 & 8.2 & 26.1 & 11.6 \\
\hline HOMA -IR & 5.9 & 5.8 & 1.9 & 26.9 & 3.9 & 7.3 & 2.2 \\
\hline Total cholesterol, (mmol/L) & 4.5 & 4.3 & 3.8 & 5.1 & 4.1 & 4.4 & 0.4 \\
\hline Triglycerides, (mmol/L) & 1.4 & 1.3 & 1.2 & 1.4 & 1.3 & 1.3 & 0.1 \\
\hline $\mathrm{HDL},(\mathrm{mmol} / \mathrm{L})$ & 1.2 & 1.0 & 0.8 & 1.6 & 1 & 1.3 & 0.2 \\
\hline $\mathrm{LDL},(\mathrm{mmol} / \mathrm{L})$ & 2.6 & 2.4 & 2.1 & 3.3 & 2.2 & 2.9 & 0.4 \\
\hline VLDL, (mmol/L) & 0.6 & 0.6 & 0.5 & 0.7 & 0.6 & 0.6 & 0.1 \\
\hline $\mathrm{Al}$ & 2.9 & 2.8 & 1.9 & 3.5 & 2.7 & 3.1 & 0.5 \\
\hline \multicolumn{8}{|c|}{ control group } \\
\hline $\begin{array}{l}\text { Fasting blood glucose level, } \\
(\mathrm{mmol} / \mathrm{L})\end{array}$ & 4.1 & 3.9 & 3.0 & 5.8 & 3.5 & 4.8 & 0.9 \\
\hline 2-hour glucose level, (mmol/L) & 3.9 & 4 & 2.8 & 5.7 & 3.2 & 4.5 & 0.9 \\
\hline $\begin{array}{l}\text { Fasting blood insulin level, } \\
\qquad(\mathrm{mcU} / \mathrm{ml})\end{array}$ & 4.7 & 4.8 & 2.6 & 6.1 & 4.1 & 5.2 & 1 \\
\hline HOMA -IR & 0.9 & 0.8 & 0.5 & 1.5 & 0.7 & 0.9 & 0.2 \\
\hline Total cholesterol, (mmol/L) & 3.8 & 3.8 & 2.9 & 4.7 & 3.4 & 4.2 & 0.5 \\
\hline Triglycerides, (mmol/L) & 1.3 & 1.3 & 1.2 & 1.5 & 1.3 & 1.4 & 0.1 \\
\hline $\mathrm{HDL},(\mathrm{mmol} / \mathrm{L})$ & 1.5 & 1.3 & 1.2 & 1.7 & 1.4 & 1.6 & 0.2 \\
\hline $\mathrm{LDL},(\mathrm{mmol} / \mathrm{L})$ & 1.7 & 1.7 & 0.8 & 2.4 & 1.4 & 2.2 & 0.5 \\
\hline $\mathrm{VLDL},(\mathrm{mmol} / \mathrm{L})$ & 0.6 & 0.6 & 0.5 & 0.6 & 0.6 & 0.6 & 0.1 \\
\hline $\mathrm{Al}$ & 1.6 & 1.5 & 0.8 & 2.3 & 1.4 & 1.9 & 0.5 \\
\hline
\end{tabular}

increased indices of fasting insulin levels and HOMA-IR. Moreover, we revealed significant increase both of these indices in TB patients who had bilateral pulmonary lesions and mycobacteria excretion, comparing to those patients who had limited lesions in their lungs and had no mycobacteria excretion.

Insulin resistance lead to increased synthesis and secretion of triglycerides, very low-density lipoprotein (VLDL) particles by the liver, an increase in plasma triglycerides, enrichment of plasma HDL particles by triglycerides and more active catabolism of triglyceride-rich HDL-C $[7,8]$. Unlike these research data we did not find an increase in plasma triglycerides level in pulmonary TB patients. Instead we revealed signs of dyslipidemia: an increase in total cholesterol level due to an increase in the LDL fraction and a decrease in HDL and increase in atherogenicity index. These changes were also more pronounced among patients with bilateral pulmonary lesions and mycobacteria excretion.

\section{CONCLUSIONS}

According to our results, patients with newly diagnosed pulmonary tuberculosis develop insulin resistance - con- dition that is a precursor to developing type 2 diabetes and metabolic disorder of lipid exchange - dyslipidemia.

Patients with bilateral pulmonary lesions and mycobacteria excretion have the most pronounced disorders of carbohydrate and lipid metabolism compared to patients with limited lesions of the lungs.

We suppose that mycobacteria excretion and bilateral lesions of lung tissue may be the markers of the degree of carbohydrate metabolism disorders in patients with pulmonary tuberculosis.

\section{REFERENCES}

1. Restrepo B.I. Diabetes and Tuberculosis. Microbiol Spectr. 2016;4(6):10.1128/ microbiolspec.TNMI7-0023-2016doi:10.1128/microbiolspec.TNMI7-0023-2016(1)

2. Yorke E., AtiaseY., Akpalu J., et al. The Bidirectional Relationship between Tuberculosis and Diabetes. Tuberc Res Treat. 2017;2017:1702578. doi:10.1155/2017/1702578

3. De Santi F., Zoppini G., Locatelli F., et al. Type 2 diabetes is associated with an increased prevalence of respiratory symptoms as compared to the general population. BMC Pulm Med 2017. 17(1):101.

4. Olga S. Shevchenko, Lilia D. Todoriko, Iryna A. Ovcharenko, et al. Dynamics of aldosterone, connective tissue reorganization and glucose level as markers for tuberculosis treatment effectiveness. Archives of the Balkan Medical Union. 2019. 54(2): 274-280. 
5. Khateeb J., Fuchs E., Khamaisi M. Diabetes and Lung Disease: A Neglected Relationship. Rev Diabet Stud. 2019 Feb 25;15:1-15. doi: 10.1900/RDS.2019.15.1.PubMed PMID: 30489598.4.

6. Cyphert T.J., Morris R.T., House L.M. et al. NF-kB-dependent airway inflammation triggers systemic insulin resistance. Am J Physiol Regul Integr Comp Physiol. 2015;309(9):R1144-R1152. doi:10.1152/ ajpregu.00442.2014

7. Mechanisms of HDL lowering in insulin resistant, hypertriglyceridemic states: the combined effect of HDL triglyceride enrichment and elevated hepatic lipase activity. Rashid S, Watanabe T, Sakaue T, Lewis GF Clin Biochem. 2003 Sep; 36(6):421-9.

8. Olga S. Shevchenko, Oksana A. Nakonechna, Liliia D. Todoriko, et al. Study of cell death and stages of leukocytes apoptosis in pulmonary tuberculosis patients with different antimycobacterial treatments. Archives of the Balkan Medical Union. 2019. 54(4):692-698

The study was performed within the research work of the Department of Phthisiology and Pulmonology of Kharkiv National Medical University "Optimization of forecasting and improving the treatment of newly diagnosed pulmonary tuberculosis based on the study of the dynamics of carbohydrate, lipid and protein metabolism" (state register \#0119U002903).

\section{ORCID and contributionship:}

Olga M. Shvets: 000-0002-8371-8258 ${ }^{\text {B,C,D,F }}$

Ganna L. Stepanenko: 0000-0002-0424-8383 ${ }^{B}$

Olga S. Shevchenko: 000-0002-5476-3981 E,F

Rostyslav S. Shevchenko: 0000-0002-6535-0939 A

Liliia D. Todoriko: 000-0002-0117-6513 ${ }^{\mathrm{A}}$

Volodumur V. Yakimets: 000-0003-3864-2423 ${ }^{\mathrm{C}}$

Oleksandra I. Choporova: 000-0003-1927-1815 ${ }^{D}$

\section{Conflict of interest:}

Authors have no conflict of interests.

\section{CORRESPONDING AUTHOR}

\section{Olga M. Shvets}

Kharkiv National Medical University

4 Nauky Avenue, 61022 Kharkiv, Ukraine

tel:+380999193762

e-mail: olga.shvets733@ukr.net

Received: 03.04.2019

Accepted: 23.04 .2020

A - Work concept and design, B - Data collection and analysis, C - Responsibility for statistical analysis,

D-Writing the article, $\mathbf{E}$-Critical review, $\mathbf{F}$ - Final approval of the article 